\title{
Comparison Of Frictional Resistance Between Interactive Self Ligating, Passive Self Ligating And Conventional Orthodontic Brackets - An In Vitro Study
}

\author{
Dr.Thariq V.K ${ }^{1}$, Dr.Dilip. $S^{2}$. \\ ${ }^{I}$ (Department of orthodontics, SRM University, India) \\ 2 (Department of orthodontics, SRM University, India)
}

\begin{abstract}
Aim: to analyze the frictional forces generated by three types of self ligating brackets; two passive (Damon 3MX and Smartclip) and one interactive (Empower) when compared to conventional orthodontic brackets using two arch wire dimensions 0.016 NiTi wire and $0.019 X 0.025$ inch stainless steel wire. Materials: The study consisted of a total of 60 brackets, 15 each of Damon 3MX, Smartclip, Empower and conventional orthodontic brackets with a slot size of .022X.028. Result: Self ligating brackets had less friction when compared with conventional brackets with both round and rectangular wires.Among the passive self ligating brackets, Damon $3 M X$ shows the least friction when tested both with round and rectangular wires when compared to Smartclip. The frictional resistance does not remain the same when tested both with round and rectangular wires, for the interactive self ligating bracket (Empower). All brackets showed higher frictional forces as the wire size increased.
\end{abstract}

Keywords: conventional stainless steel brackets, fixed appliance therapy, frictional resistance, passive self ligating brackets, self ligating brackets.

\section{Introduction}

The speciality of orthodontics has been going through a period of considerable research interest in the role of friction during tooth movement. During the past thirty years, studies have focused on both the contact between the wire and the bracket- or tube-slot as a potential source of frictional resistance during sliding mechanics and the many associated factors that can affect that resistance to tooth movement. Previous experiments have identified variables in the archwire, bracket, ligature and oral environment as contributors to frictional forces.

In the orthodontic literature, friction was discussed as early as 1960 when Stoner $^{1}$ warned of the difficulty in determining the amount of force to be applied to a tooth because of the role of frictional resistance. Understanding of friction impairing tooth movement is largely based on long-standing theories, by Leonardo $\mathrm{Da}$ Vinci, Guillaume Amontons, and Charles-Augustin Coulomb.

Friction is the resistance to motion that occurs when an object moves tangentially against other. ${ }^{2}$ During fixed appliance therapy, the main force that contrasts the tooth movement is the frictional force developed between the interface of the bracket slot and arch wire. ${ }^{3}$

The total contact-force between the objects is expressed as two components when there is attempted or actual relative displacement between surfaces in contact. One component, the normal force, is a pushing force with an orientation perpendicular to the shared contact-surface. The frictional force component impedes the motion between the surfaces and is, therefore, opposite in direction to that of intended or actual motion. ${ }^{4}$

A series of method have been proposed with the aim of limiting friction at the bracket/wire/ligature interface, such as loosely tied stainless steel ligatures, self ligating brackets (SLB), and unconventional ligature systems. The disadvantages of conventional ligating system include high friction, force decay, potential impediment to oral hygeiene and time consuming among others. To overcome these disadvantages self ligating brackets were introduced.

Self ligating brackets (SLB) are ligature-less bracket systems that have a mechanical device built into the bracket to close the edgewise slot. ${ }^{5}$ Thus, self-ligating brackets have an inbuilt metal labial face which can be opened or closed. ${ }^{6}$ Classification of self ligating brackets includes those that have a spring clip that presses against the archwire ("active" or "interactive" Self ligating brackets) and those in which the self-ligating clip does not press against the archwire ("passive" self ligating brackets). Passive Self ligating brackets have consistently shown a smaller amount of friction than active self ligating brackets, with the exception of the use of undersized round archwires. ${ }^{7,8}$

Self-ligation was initially described by Stolzenberg in $1935 .^{9}$ The first self-ligation bracket was called the Russell-Lock edgewise attachment. Self-ligation lost its popularity until the 1970s when Ormco introduced 
the Edgelock. It wasn't until the 1980s that self-ligation gained widespread use with the introduction of Forsadent and SPEED in 1980. ${ }^{9,10}$

The newly introduced so called interactive self ligating brackets combine the advantages of passive and active self ligating brackets. They can lock (passive) and seat (active) the arch wires into the base of the slot with low functional friction so as to fully express the prescription. ${ }^{11,12}$ During space closure the anteriors can be made active for proper torque control and posteriors are passive to allow for reduced friction. Ease of opening, maximum retention, accurately contoured pads, low profile particularly in anteriors, reduced treatment time, reduced chair side time are some of the other advantages of interactive self ligating brackets . Very little research has been done using these brackets.

The aim of this invitro study was to analyze the frictional forces generated by three types of self ligating brackets ; two passive and one interactive when compared to conventional orthodontic brackets using two arch wire dimensions.

1. INTRODUCTION

2. AIM AND OBJECTIVES

3. MATERIALS AND METHODS

4. RESULTS

5. CONCLUSION

6. ACKNOWLEDGEMENTS

7. BIBLIOGRAPHY

II. Headings

\section{Aim And Objectives}

To evaluate the frictional resistance of two types of passive self ligating brackets, one type of interactive self ligating bracket and conventional orthodontic brackets.

To compare the frictional resistance between the four groups.

\section{Materials And Method}

Four different brackets were used for the study: Conventional orthodontic brackets (American Orthodontics), Empower (American orthodontics), Smart clip (3m), Damon 3MX (Ormco). The two different types of arch wires used for the study were: $0.016 \mathrm{NiTi}$ (American Orthodontics) and 0.019x0.025 SS (American Orthodontics). Sixty arch wire segments, with a .019 x .025 inch stainless steel and 0.016 NiTi were used. $0.016 \mathrm{NiTi}$ wire was used since they are used during alignment stage and 0.019 X $0.025 \mathrm{SS}$ wires were used since they are used during retraction stage Arch wire were ligated to the conventional bracket slot with stainless steel ligatures tightly and then unwound a quarter turn ${ }^{13,14}$.

\section{Methodology}

A prefabricated commercial 4 inch $x 2$ inch acrylic plate was used. At one end of the plate a horizontal and vertical line was drawn, the point of intersection of these two lines was taken as a point of bracket placement. The brackets were placed in this point and then stabilized by means of an industrial adhesive.

Instron testing machine was used with $10 \mathrm{~kg}$ load cell to determine the frictional force levels. The machine was adjusted in the tensile mode and the force levels were measured in kilograms in a digital read out. The Instron testing machine not only measured the kilogram of tensile force required to pull the wire through fixed bracket but also gave the tracking distance as a digital read out in lengths of millimeter as the cross head travelled superiorly up the wire.

A wire of about $10 \mathrm{~mm}$ length was taken and placed in the bracket and ligated. The other end of acrylic plate was mounted on to the lower grip of Instron testing machine. The free end of the arch wire was fixed to the upper grip of Instron testing machine which was connected to the load cell. It is cleaned with $95 \%$ alcohol and air dried ${ }^{15}$ to maintain asepsis and moisture control.

Each wire was pulled through the bracket slot by a distance of $10 \mathrm{~mm}$ at a speed of $5 \mathrm{~mm}$ per $\min ^{16}$, the force levels were recorded from the digital marker. The arch wire and bracket were tested such that a new bracket was used for every test and then discarded. This was done in order to eliminate dimensional changes. All the tests were done in dry conditions. Frictional resistance was evaluated in dry states against $0.019 \times 0.025$ inch rectangular stainless steel arch wire and 0.016 inch round NiTi arch wire and the results were tabulated. 


\section{Results}

Table I

Oneway

DESCRIPTIVES

FRICTIONAL RESISTANCE OF 0.016 NITI WIRE

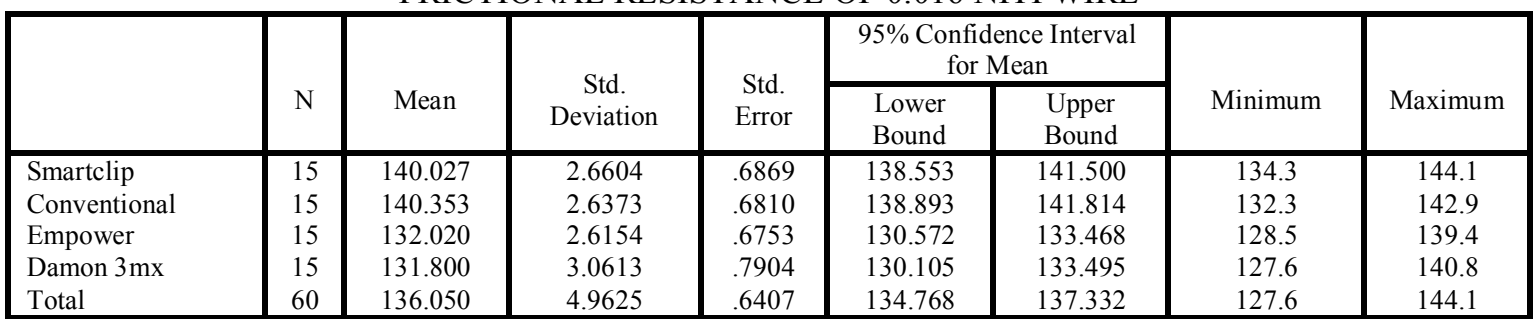

Table I shows mean and standard deviation for $0.016 \mathrm{NiTi}$ wire

Table II

ANOVA

FRICTIONAL RESISTANCE OF 0.016 NiTi WIRE

\begin{tabular}{|l|c|c|c|c|c|}
\hline & $\begin{array}{c}\text { Sum of } \\
\text { squares }\end{array}$ & Df & Mean square & F & Sig \\
\hline Between Groups & 1029.539 & 3 & 343.180 & 45.387 & .000 \\
Within Groups & 423.431 & 56 & 7.561 & \\
Total & 1452.970 & 59 & & \\
\hline
\end{tabular}

Table II shows comparison between groups is statistically significant

Table III

Post Hoc Tests Multiple Comparisons

Dependent Variable: FRICTIONAL RESISTANCE OF 0.016 NiTi WIRE Turkey HSD

\begin{tabular}{|c|c|c|c|c|c|c|}
\hline \multirow[b]{2}{*}{ (I)BRACKETS } & \multirow[b]{2}{*}{ (J)BRACKETS } & \multirow[b]{2}{*}{$\begin{array}{c}\text { Mean Difference } \\
(\mathrm{I}-\mathrm{J})\end{array}$} & \multirow[b]{2}{*}{ Std . Error } & \multirow[b]{2}{*}{ Sig } & \multicolumn{2}{|c|}{ 95\% Confidence Interval } \\
\hline & & & & & $\begin{array}{l}\text { Lower } \\
\text { Bound }\end{array}$ & Upper Bound \\
\hline \multirow[t]{3}{*}{ SMARTCLIP } & CONVENTIONAL & -.3267 & 1.0041 & .988 & -2.985 & 2.332 \\
\hline & EMPOWER & $8.0067^{*}$ & 1.0041 & .000 & 5.348 & 10.665 \\
\hline & DAMON $3 \mathrm{MX}$ & $8.2267^{*}$ & 1.0041 & .000 & 5.568 & 10.885 \\
\hline \multirow{3}{*}{$\begin{array}{l}\text { CONVENTIO } \\
\text { NAL }\end{array}$} & SMARTCLIP & .3267 & 1.0041 & .988 & -2.332 & 2.985 \\
\hline & EMPOWER & $8.3333^{*}$ & 1.0041 & .000 & 5.675 & 10.992 \\
\hline & DAMON $3 \mathrm{MX}$ & $8.3333 *$ & 1.0041 & .000 & 5.895 & 11.212 \\
\hline \multirow[t]{3}{*}{ EMPOWER } & SMARTCLIP & $-8.0067 *$ & 1.0041 & .000 & -10.665 & -5.348 \\
\hline & CONVENTIONAL & $-8.3333^{*}$ & 1.0041 & .000 & -10.992 & -5.675 \\
\hline & DAMON 3MX & $.2200 *$ & 1.0041 & .996 & -2.439 & 2.879 \\
\hline \multirow[t]{3}{*}{ DAMON 3MX } & SMARTCLIP & $-8.2267 *$ & 1.0041 & .000 & -10.885 & -5.568 \\
\hline & CONVENTIONAL & $-8.5533^{*}$ & 1.0041 & .000 & -11.212 & -5.895 \\
\hline & EMPOWER & -.2200 & 1.0041 & .996 & -2.879 & 2.439 \\
\hline
\end{tabular}

*The mean difference is significant at the .05 level

Table III multiple comparison shows the comparison between Conventional brackets and Smartclip and Empower and Damon 3MX are not statistically significant

Table IV

Oneway Descriptives

FRICTIONAL RESISTANCE OF 0.019 X 0.025 SS WIRE

\begin{tabular}{|c|c|c|c|c|c|c|c|c|}
\hline & \multirow[b]{2}{*}{$\mathrm{N}$} & \multirow[b]{2}{*}{ Mean } & \multirow[b]{2}{*}{$\begin{array}{c}\text { Std. } \\
\text { Deviation }\end{array}$} & \multirow[b]{2}{*}{$\begin{array}{l}\text { Std. } \\
\text { Error }\end{array}$} & \multicolumn{2}{|c|}{$\begin{array}{l}95 \% \text { Confidence Interval } \\
\text { for Mean }\end{array}$} & \multirow[b]{2}{*}{ Minimum } & \multirow[b]{2}{*}{ Maximum } \\
\hline & & & & & $\begin{array}{l}\text { Lower } \\
\text { Bound }\end{array}$ & $\begin{array}{l}\text { Upper } \\
\text { Bound }\end{array}$ & & \\
\hline $\begin{array}{l}\text { Conventional } \\
\text { Brackets }\end{array}$ & 15 & 385.507 & 3.2890 & .8492 & 383.685 & 387.328 & 379.8 & 391.0 \\
\hline Smartclip & 15 & 372.247 & 6.1331 & 1.5836 & 368.850 & 375.643 & 361.1 & 382.5 \\
\hline Empower & 15 & 383.513 & 3.4155 & .8819 & 381.622 & 385.405 & 376.8 & 391.4 \\
\hline Damon $3 \mathrm{mx}$ & 15 & 319.353 & 8.3158 & 2.1471 & 314.748 & 323.958 & 301.8 & 334.6 \\
\hline Total & 60 & 365.155 & 27.7089 & 3.5722 & 357.997 & 372.313 & 301.8 & 391.4 \\
\hline
\end{tabular}

Table IV shows mean and standard deviation for $0.019 \times 0.025$ SS wire 
Table V

ANOVA

FRICTIONAL RESISTANCE OF $0.019 \times 0.025$ SS WIRE

\begin{tabular}{|l|c|c|c|c|c|}
\hline & Sum of & & & & F \\
\hline Between Groups & 43489.547 & 3 & 14496.516 & 448.630 & \\
Within Groups & 1809.521 & 56 & 32.313 & & \\
Total & 45299.068 & 59 & & \\
\hline
\end{tabular}

Table V shows comparison between groups is statistically significant

Post Hoc Tests

Table VI

Multiple Comparisons

Dependent Variable : FRICTIONAL RESISTANCE OF

0.019 X 0.025 SS WIRE

Turkey HSD

\begin{tabular}{|c|c|c|c|c|c|c|}
\hline \multirow[b]{2}{*}{ (I)BRACKETS } & \multirow[b]{2}{*}{ (J)BRACKETS } & \multirow[b]{2}{*}{$\begin{array}{c}\text { Mean Difference } \\
(I-J)\end{array}$} & \multirow[b]{2}{*}{ Std. Error } & \multirow[b]{2}{*}{ Sig } & \multicolumn{2}{|c|}{$95 \%$ Confidence Interval } \\
\hline & & & & & $\begin{array}{l}\text { Lower } \\
\text { Bound }\end{array}$ & $\begin{array}{l}\text { Upper } \\
\text { Bound }\end{array}$ \\
\hline \multirow[t]{3}{*}{ SMARTCLIP } & DAMON 3MX & $52.8933^{*}$ & 2.0757 & .000 & 47.397 & 58.389 \\
\hline & CONVENTIONAL & $-13.2600^{*}$ & 2.0757 & .000 & -18.756 & -7.764 \\
\hline & EMPOWER & $-11.2667^{*}$ & 2.0757 & .000 & -16.763 & -5.771 \\
\hline \multirow[t]{3}{*}{ DAMON 3MX } & SMARTCLIP & $-52.8933^{*}$ & 2.0757 & .000 & -58.389 & -47.397 \\
\hline & CONVENTIONAL & $-66.1533 *$ & 2.0757 & .000 & -71.649 & -60.657 \\
\hline & EMPOWER & $-64.1600 *$ & 2.0757 & .000 & -69.656 & -58.664 \\
\hline \multirow[t]{3}{*}{ CONVENTIONAL } & SMARTCLIP & $-13.2600^{*}$ & 2.0757 & .000 & -10.665 & 18.756 \\
\hline & DAMON 3MX & $66.1533^{*}$ & 2.0757 & .000 & 60.657 & 71.649 \\
\hline & EMPOWER & $1.9933 *$ & 2.0757 & .772 & -3.503 & 7.489 \\
\hline \multirow[t]{3}{*}{ EMPOWER } & SMARTCLIP & $-11.2667 *$ & 2.0757 & .000 & 5.771 & 16.763 \\
\hline & DAMON 3MX & $64.1600 *$ & 2.0757 & .000 & 58.664 & 69.656 \\
\hline & CONVENTIONAL & -1.993 & 2.0757 & .772 & -7.489 & 3.503 \\
\hline
\end{tabular}

*The mean difference is significant at the .05 level

Table VI multiple comparison shows except the comparison between Empower and conventional all other comparisons are statistically significant.

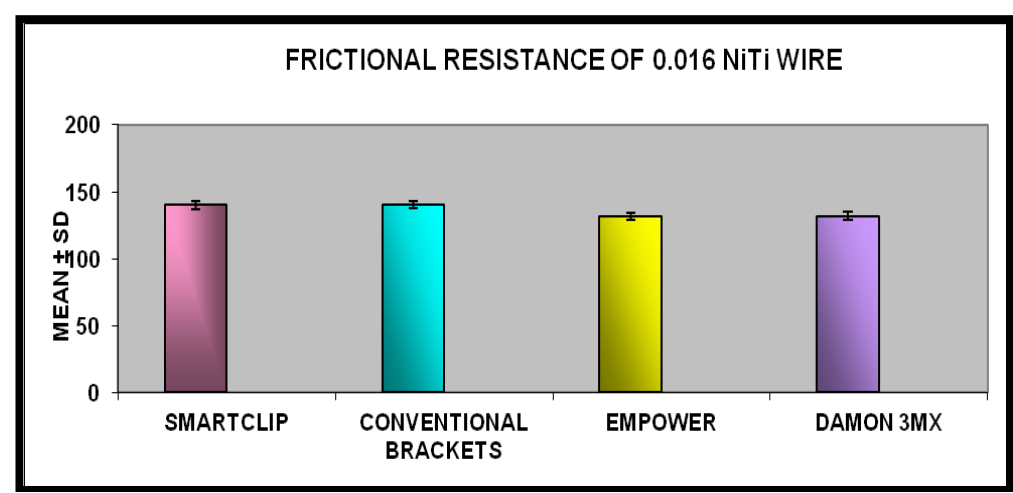

GRAPH-1

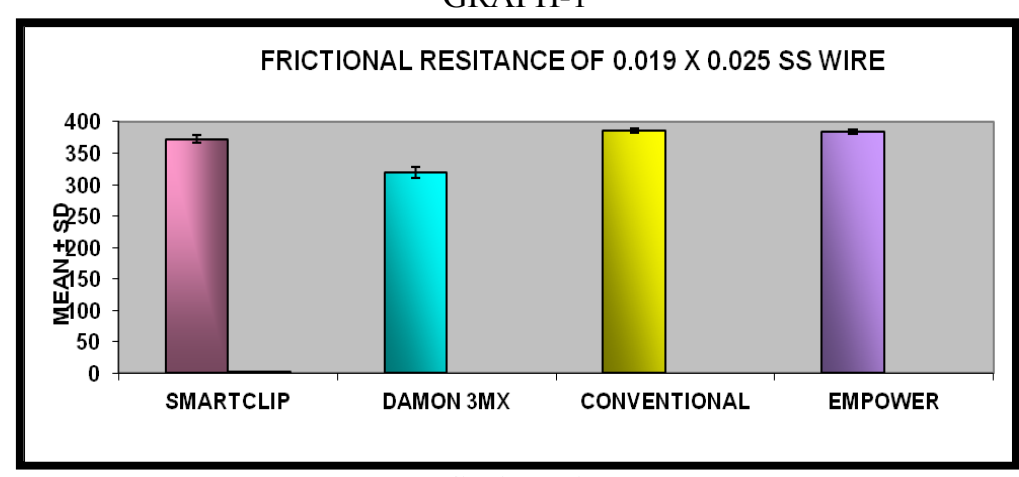

GRAPH-2 


\section{Conclusion}

Friction at the bracket-wire interface prevent the attainment of optimal force levels in the supporting tissues and thereby decrease the tooth movement and increases the anchorage strain. Therefore, a decrease in frictional resistance tends to benefit the hard and soft tissue response. Self ligating brackets are introduced to the dentistry with the advantage of having reduced frictional resistance compared to conventional brackets.

The purpose of this in vitro study was to analyze the frictional forces generated by three types of self ligating brackets ; two passive (Damon 3MX and Smartclip) and one interactive (Empower) when compared to conventional orthodontic brackets using two arch wire dimensions $0.016 \mathrm{NiTi}$ wire and 0.019X0.025 inch stainless steel wire. The study consisted of a total of 60 brackets, 15 each of Damon 3MX, Smartclip, Empower and conventional orthodontic brackets with a slot size of .022X.028.

The frictional resistance of different groups in ascending order with $0.016 \mathrm{NiTi}$ wire was Damon 3MX, Empower, Smartclip and conventional stainless steel brackets and with 0.019 x 0.025 inch SS wire was Damon 3MX, Smartclip, Empower and conventional stainless steel brackets.

The results of our study is as follows that

1) Self ligating brackets had less friction when compared with conventional brackets with both round and rectangular wires.

2) Among the passive self ligating brackets, Damon 3MX shows the least friction when tested both with round and rectangular wires when compared to Smartclip.

3) The frictional resistance does not remain the same when tested both with round and rectangular wires, for the interactive self ligating bracket (Empower).

4) All brackets showed higher frictional forces as the wire size increased.

Data suggest that sliding mechanics are best executed with self ligating brackets than conventional brackets. Moreover these data reveal the usefulness of interactive self ligating brackets when used in anterior teeth during retraction and finishing stages where some amount of friction is desirable.

First of all, I thank God Almighty for his love \& blessings.

\section{Acknowledgements.}

I shall forever remain indebted to my teachers, Dr. K. Ravi, MDS, Professor \& HOD, Dr. M. Vasanthakumar, M.D.S, Principal, Dr. R. Krishnaraj, MDS, Professor, Dr. S. Dilip, MDS Professor, Dr. S. Srinivas, MDS, Reader, Dr. Sangeetha.D, MDS Reader, Dr. Edeinton . A, MDS Reader Dr.R. Poornima, MDS, Senior Lecturer, Dr.R. Meera, MDS, Senior Lecturer for believing in me, for teaching me with patience and understanding, for their overwhelming help and meticulous care in correcting my mistakes with their valuable advice and friendly encouragement.

Finally, I would like to thank my parents, my beloved wife and my little daughter for fulfilling all my dreams and for all their support and timely help.

\section{Bibliography}

[1]. Stoner MM. Force control in clinical practice. Am J Orthod 1960;46:163-168

[2]. Loftus BP, Artun J, Nicholls JI, Alonzo TA, Stoner JA. Evaluation of friction during sliding tooth movement in various bracket-arch wire combinations. Am J Orthod Dentofacial Orthop 1999;116:336-345.

[3]. Ogata RH, Nanda RS, Duncanson MG Jr, Sinha PK, Currier GF. Frictional resistances in stainless steel bracket-wire combinations with effects of vertical deflections. Am J Orthod Dentofacial Orthop 1996;109:535-542.

[4]. Frank CA, Nikolai RJ. A comparative study of frictional resistances between orthodontic bracket and arch wire. Am J Orthod 1980;78:593609.

[5]. Cacciafesta V, Sfondrini MF, Ricciardi A, Scribante A, Klersy C, AuricchioF. Evaluation of friction of stainless steel and esthetic selfligating brackets in various racket-archwire combinations. Am J Orthod Dentofacial Orthop 2003;124: 395-402.

[6]. Sayeh Ehsani; Marie-Alice Mandich; Tarek H. El-Bialy; Carlos Flores-Mir Frictional Resistance in Self-Ligating Orthodontic Brackets and Conventionally Ligated Brackets -A Systematic Review. Angle Orthod 2009; 79: 592-601.

[7]. Pizzoni L, Ravnholt G, Melsen B. Frictional forces related to self-ligating brackets. Eur J Orthod 1998;20:283-291

[8]. Thomas S, Sherriff M, Birnie D. A comparative in vitro study of the frictional characteristics of two types of self-ligating brackets and two types of pre-adjusted edgewise brackets tied with elastomeric ligatures. Eur J Orthod 1998;20:589- 596.

[9]. Harradine NW. Self-ligating brackets and treatment efficiency. Clin Orthod Res 2001;4:220-227.

[10]. Stolzenberg J. The Russell attachment and its improved advantages. Int J Orthod 1935;21:837-840.

[11]. Voudouris JC. Flow Mechanics and Biological Tooth Movement. In: Kuftinec MM, ed. Excellence and Efficiency Interactive Twin SelfLigation: Orthopedic-Muscle and Gnathological Biomechanics in Clinical Orthodontics. Toronto, On: ISL and Dentofacial Orthopedic Publications Co; 2007:13- 17

[12]. Voudouris JC. Seven clinical principles of interactive twin mechanisms. J Clin Orthod 1997;31:55-65

[13]. Nathawut Sirisaowaluk, OlenaKravchuk, Christopher TC. The influence of ligation on frictional resistance to sliding during repeated displacement. Aust Orthod J 2006; 22: 141-146.

[14]. Baker KL, Nieberg LG, Weimer AD, Hanna M. Frictional changes in force values caused by saliva substitution Am J Orthod Dentofacial Orthop 1987;91:316-20.

[15]. Bednar JR, Gruendeman GW, Sandrik JL. A comparative study of frictional forces between orthodontic brackets and arch wires. Am J Orthod Dentofacial Orthop 1991;100:513-22.

[16]. Braun S, Bluestein M , Moore K, Benson G Friction on perspectives. Am J Orthod Dentofacial Orthop 1999;115:619-627. 